ciated with these promoters in an inactive form. Further observations from Struhl and collaborators ${ }^{14}$ have shown that the ATP-dependent chromatin remodeling complex RSC, which is generally recruited to promoters upon activation, is bound to a number of promoters prior to their transcriptional activation.

The scenario emerging from these observations is that chromatin-modifying enzymes may associate with rapidly inducible or repressible promoters prior to activation or repression, and may somehow be kept in an inactive state at these promoters. Upon transcriptional induction (or repression), the production of small signaling molecules such as $\mathrm{IP}_{4}$ and $\mathrm{IP}_{5}$ could provide a means of rapidly modulating the transcription of target genes. Interestingly, many of the genes to which RPD3 binds but remains inactive are rapidly repressed when yeast are exposed to environmental stresses ${ }^{15}$.
Perhaps stress modulates the level of some signaling molecule that relieves RPD3 from its inactive state at the promoters of highly expressed genes. The identity of such a signaling molecule - if indeed it exists - is, of course, a mystery. However, rapidly regulatable promoters clearly display pre-localization of chromatin-modifying proteins. Coupled with evidence that small molecules can regulate chromatin-remodeling enzymes, the data suggest that the controlled synthesis of small molecule regulators of chromatin modifiers may be one of the means whereby cells could rapidly modulate gene expression in response to environmental stimuli.

Oliver J. Rando, Tian H. Chi and Gerald R. Crabtree are in the Department of Developmental Biology and the Department of Pathology, Stanford University, Stanford, California 94305, USA. Correspondence should be addressed to G.R.C. e-mail: crabtree@cmgm.stanford.edu

1. Narlikar, G.J., Fan, H.Y. \& Kingston, R.E. Cell 108, 475-487 (2002).

2. Cosma, M.P., Tanaka, T. \& Nasmyth, K. Cell 97, 299-311 (1999).

3. Zhao, K. et al. Cell 95, 625-636 (1998).

4. Shen, X., Xiao, H., Ranallo, R., Wu, W.H. \& Wu, C. Science. 299, 112-114 (2003).

5. Steger, D.J., Haswell, E.S., Miller, A.L., Wente, S.R. \& O'Shea, E.K. Science. 299, 114-116 (2003).

6. Divecha, N. \& Irvine, R.F. Cell 80, 269-278 (1995)

7. Chi, T.H. et al. Nature 418, 195-199 (2002).

8. Rando, O.J., Zhao, K., Janmey, P. \& Crabtree, G.R. Proc. Natl. Acad. Sci. USA 99, 2824-2829 (2002).

9. Odom, A.R., Stahlberg, A., Wente, S.R. \& York, J.D. Science 287, 2026-2029 (2000).

10. Dubois, E., Dewaste, V., Erneux, C. \& Messenguy, F. FEBS Lett. 486, 300-304 (2000).

11. York, J.D., Odom, A.R., Murphy, R., Ives, E.B. \& Wente, S.R. Science 285, 96-100 (1999).

12. Kurdistani, S.K., Robyr, D., Tavazoie, S. \& Grunstein, M. Nat. Genet. 31, 248-54 (2002).

3. Bernstein, B.E., Tong, J.K. \& Schreiber, S.L. Proc. Natl. Acad. Sci. USA 97, 13708-13713 (2000)

4. Ng, H.H., Robert, F., Young, R.A. \& Struhl, K. Genes Dev. 16, 806-819 (2002).

15. Gasch, A.P. et al. Mol. Biol. Cell 11, 4241-4257 (2000). 6. Inokuchi, S. \& Imboden, J.B. J. Biol. Chem. 265, 5983-5989 (1990).

17. Bultman, S. et al. Mol. Cell 6, 1287-1295 (2000)

18. Reyes, J.C. et al. EMBO J. 17, 6979-6991 (1998).

\title{
Tick-tock goes the acetylation clock
}

Mice, humans and many other organisms have internal biological clocks that control their sleeping patterns, breeding cycles, hormonal circuits and other physiological processes. A remarkable feature of the 24-hour circadian clock is that, in principle, it can function in the absence of any external cues. For instance, mice will continue to display day/night-like locomotor activity in total darkness. And, while sunlight does reset the clock, after travelling between time zones humans can nonetheless struggle with jet-lag for quite some time. At the heart of this regulatory process lie a set of transcription factors whose activity oscillates in a choreographed and well-rehearsed manner. A series of feedback loops moderates the timely expression, intracellular location and degradation of various regulatory proteins, including products of the period (Per), clock, timeless and cryptochrome genes. The end result is a molecular circuit that exquisitely regulates the transcription of these genes at appropriate times of the day. Like clockwork, in fact.
If transcription plays a crucial role in all this wizardry, then what is the molecular basis for the alternating high and low levels of gene-specific transcription that are observed? In a recent Nature paper, Etchegaray et al. (Nature 421, 177-182; 2003) show that circadian transcription is associated with rhythmic changes in histone acetylation at the promoters of the key clock components. There is a correlation between the level of histone $\mathrm{H} 3$ acetylation at the Per1 promoter (Ac-H3) and the binding of RNA polymerase II (Pol II). Furthermore, steady-state changes in Per1 mRNA levels reflect the increased polymerase activity at Per1 towards the end of the light-phase of the day (lower panel, relative abundance). This suggests a synchrony between H3 acetylation and transcription. But how are these timed changes in acetylation brought about? The authors find that the activator protein Clock, a transcription factor that binds the Per1 promoter, interacts with the p300 histone acetyltransferase with $\sim 5$-fold higher

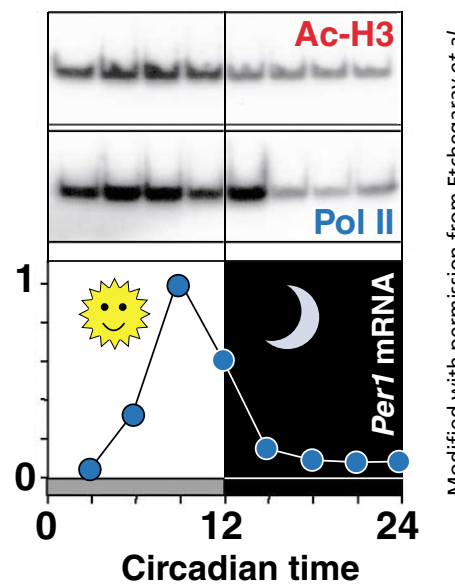

efficiency at circadian time 6 versus 18 hours. Decreased Clockp300 interactions may therefore account for the nocturnal decreases in Per1 acetylation and transcription. Together with an earlier report on light-induced chromatin modifications by the Allis and SassoneCorsi laboratories (Nat. Neurosci. 3, 1241-1247; 2000), the study clearly advocates the idea that histone acetylation is one of the essential cogs which helps our circadian clock to keep time reliably.

Andreas G. Ladurner 